\title{
Conceptual Framework of Organisational Factors on Explicit and Tacit Knowledge Sharing
}

\author{
Preeti Choudhary ${ }^{1}$, Lovy Sarikwal ${ }^{2}$ \\ ${ }^{1}$ Research Scholar, School of Management, Gautam Buddha University, Greater Noida, India) \\ ${ }_{2}^{2}$ (Assistant professor, School of Management, Gautam Buddha University, Greater Noida, India)
}

\begin{abstract}
Knowledge is an important organizational source that provides the sustainable competitive advantage in a competitive and dynamic economy. Knowledge sharing has become an essence for knowledge management. It is as an activity to disseminate the information, to collaborate with others to solve problems, develop innovative ideas, or implement policies or procedures. However, previous studies have shown that individuals are reluctant to share their knowledge as they consider that they will lose their status in the organization if they share knowledge with others. Therefore, in the execution of knowledge management activities, knowledge sharing is recognized as the most reluctant and difficult factor. Based on the literature review we developed a conceptual framework that identifies key organizational factors which significantly influence the explicit and tacit knowledge sharing. This study categorized the organizational factors into three parts as most repeatedly used factors, less researched factors and least researched factors and examines their relationships with knowledge sharing. Thus, the purpose of this study is to examine the relationship between key organizational factors and knowledge sharing. The paper concludes with a discussion of emerging issues, new research directions with some suggestions for future research.
\end{abstract}

Keywords: knowledge sharing, knowledge management, Organizational Factors, Explicit Knowledge, Tacit knowledge

\section{Introduction}

Knowledge is a critical organizational resource that provides a sustainable competitive advantage in a competitive and dynamic economy [1], [2], [3], [4], [5]. It is as an activity to disseminate the information, to collaborate with others to solve problems, develop innovative ideas, or implement policies or procedures. Effective managing and sharing of knowledge has the power to improve individual's lives and society [6]. Despite the fact, individuals do not share their knowledge and reluctant to share it because they consider it important for themselves as it can help them to remain valuable in the organization [7]. Many researchers and practitioners have also found that the existence of technology alone is not sufficient in encouraging knowledge sharing behavior among employees, human dimensions must be considered. Thus we have emphasis on organizational factors that have cited as significant influences on employees knowledge sharing behavior in any organization.This paper discusses the relationship between knowledge sharing and organizational factors in three ways. 1). we review and integrate the literature from different fields examining how organizational factors influences knowledge sharing via explicit and tacit knowledge. 2). we identify the critical factors and categorized them into 3 parts as most researched area, less researched area and least researched area influencing knowledge sharing among employees within organizations. 3).Besides reviewing, some new factors are also included in this study.

\section{Literature Review}

Knowledge is considered as the economic resource for an organization. It is a process in which people interact and intentionally make knowledge available to each other and get something done better, more quickly or more efficiently. Knowledge that is possessed by an individual is more valuable when it is shared with others thus becoming a part of collective memory of an organization [8]. As a result, KS will affect organization's long-run performance and competitiveness. Although knowledge sharing is crucial but still individuals do not share their knowledge because they consider it important for themselves [9] as it can help them to remain valuable in the organization [7]. Knowledge shared is either tacit or explicit knowledge [10]. Tacit knowledge resides in the mind of human being that acquired by interacting with others. It is unspoken and hidden [11] and deeply rooted in action, procedures, routines, commitment, ideals, values, and emotions [12], [13]. On the other hand, explicit knowledge is systematic knowledge often in written form such as books, documents and reports. Explicit knowledge can easily be codified, stored, and transferred across time and space independent of individuals [14]. Never the less, due to varied individual behavior, KS cannot happen easily. 


\subsection{Organizational Factors}

Knowledge has been extensively recognized as the central foundation for generating an organization's defensible economical benefit. It reveals that organizational factors have direct relationship with knowledge sharing behavior of the employees. Few organizational factors are as follows:

2.1.1. Culture: Organizational culture has a strong influence on knowledge-sharing behavior [15]. In the organizational environment, organizational culture represents the unspoken norms and shared values, beliefs, daily practices that shape the patterns and qualities of interactions between employees at different hierarchical levels [16]. It is the most frequently-cited factor supporting KS [17], [18], and [16]. A KS culture is also a key element in preventing the loss of human capital because it allows employees to learn and transfer their skills, knowledge, and experience to others in the organization. However, organizational culture has many dimensions and it may be influence knowledge sharing positively or negatively [19], depending on the culture type. It also plays an important role on individuals' decisions to share tacit knowledge.

2.1.2. Organizational structure: A flexible organizational structure encourages knowledge sharing while a rigid structure often has the unintended consequence of inhibiting such practices [20]. Researchers have shown that knowledge sharing may be facilitated by having a less centralized organizational structure [21].

2.1.3. Rewards and incentives: Researchers [22] have posited that reward is one of the most effective method of encouraging employees to share their knowledge to other employees [23], [21]. Organizational rewards and incentives such as promotion, bonus, and higher salary have been shown to be positively related to the frequency of knowledge contribution [5]. However, some studies found a positive impact of rewards on KS [24], [25], while others found negative influences [26], [27], [28], [29].

2.1.4. Social networking/environment: Social environment refers to the social relationships in which individuals are embedded [30]. It is important to study social relationships in organizational contexts because employees might exert pressure on co-workers' behavior, and employees might also be influenced by pressure from other employees [15]. An individual is more likely to be influenced by another when the information provided is viewed as credible. On the other hand, tacit knowledge sharing is a genuine human interaction; hence, the ways in which employees perceive their social environment will influence their decision to engage in tacit knowledge-sharing behavior [15].

2.1.5. Top management support: Top management support specific to KS is a better predictor of employee KS behavior [32]. It affects both the level and quality of knowledge sharing [31], [5]. Managers are increasingly required to stimulate subordinates to voluntarily share their knowledge and experience, and convert the shared knowledge into organizational assets.

2.1.6. Leadership: Leadership is a relevant factor influencing knowledge sharing [33]. Reference [34] discussed the role of leadership in encouraging and nurturing the knowledge sharing behavior. This study also highlighted that empowering leadership not only leads to knowledge sharing, but also positively influences efficacy, consequently leading to better team performance. Therefore, leadership is a factor that plays an important role in affecting individuals' cognitive state and helping in sharing knowledge with others or contributing to KM system [8].

2.1.7. Work process: It is difficult to capture knowledge as people are reluctant or refused to contribute their knowledge or are incapable to deliver their knowledge. Researchers suggested the best way to make people capable to share, which is to contribute knowledge as part of their work process [6].

2.1.8. Values: Values are seen as an important driver in sharing knowledge [8] that ultimately affects knowledge sharing behavior. It is the process of espousement and enactment by the organization and through the internalization by the individual, that values such as dialogue can affect knowledge sharing behavior [35]. Additionally, values are seen as an important driver in the use of information technology in sharing knowledge [36], [8].

Table 1: Organisational Factors Influencing Knowledge Sharing

\begin{tabular}{|l|l|}
\hline Organisational Factors & Authors \\
\hline Culture & Carneiro 2000; DeLong and Fahey, 2000; Chow et al., 2000; Iyer and Aronson, 2000; Gupta \\
& and Govindarajan 2000; McDermott and O'Dell 2001; Goh 2002; Sveiby and Simons, 2002; \\
& Low et al., 2003; Gupta, Cummings and Teng, 2003; Janz and Prasarnphanich, 2003; DeLong, \\
& 2004; Taylor and Wright, 2004; Norizah et al., 2005; Small and Sage, 2006; Al-Alawi et al., \\
& 2007; Hall and Goody, 2007; Bakhari and Zawiyah, 2008; Huang et al., 2008; Huang et al., \\
& 2008; Hoof and Huysman, 2009; Hsieh et al., 2009; Wang and Noe, 2010; Suppiah and Sandhu, \\
& 2011; Yiu and Law, 2012; Chen and Cheng, 2012; Kathiravelu, 2013; Aris, 2013; Alhalhouli et \\
& al., 2014; \\
\hline Structure/Structural & Tagliaventi \& Mattarelli, 2006; Kim \& Lee, 2006; Bakhari and Zawiyah, 2008; Wang and Noe, \\
\hline diversity & 2010 \\
\hline Rewards & Bock and Kim, 2001; Hall, 2001; Jones, 2001; Lee and Al-Hawamdeh, 2002; Zarraga and \\
& Bonache, 2003; Norizah et al., 2005; Bock et al., 2005; Kankanhalli et al., 2005; Hartini, \\
& Normala, Sobry, 2006; Kim and Lee, 2006; Jones et al., 2006; Al-Alawi et al., 2007; Quigley, \\
& Tesluk, Locke and Bartol, 2007; Kulkarni et al., 2007; Bakhari and Zawiyah, 2008; Abdullah et \\
\hline
\end{tabular}




\begin{tabular}{|c|c|}
\hline & $\begin{array}{l}\text { al., 2008; He and Wei, 2009; Wang et al., 2009; Juhana et al., 2009; Alam, et. Al., 2009; Weir } \\
\text { and Hutchings, 2010; Wang and Noe, 2010; Yiu and Law, 2012; Wei, et. Al., 2012; } \\
\text { Kathiravelu, } 2013\end{array}$ \\
\hline Leadership & $\begin{array}{l}\text { Low et al., 2003; Srivastava, Bartol, and Locke, 2006; Sondergaard et al., 2007; Stoddart's, } \\
\text { 2007; Jahani et al., 2011; Yiu and Law, 2012; Suveatwatanakul, 2013; Alhalhouli et al., 2014; }\end{array}$ \\
\hline Mentoring & Norizah et al., 2005 \\
\hline Management System & Low et al., 2003; Norizah et al., 2005; Chennamaneni, 2006; Aris, 2013 \\
\hline $\begin{array}{l}\text { Organizational } \\
\text { Environment }\end{array}$ & Hartini, Normala, Sobry, 2006 \\
\hline Work Process & $\begin{array}{l}\text { Lee and Al- Hawamdeh, 2002; Norizah et al., 2005; Bakhari and Zawiyah, 2008; Bakhari and } \\
\text { Zawiyah, } 2008\end{array}$ \\
\hline Office Layout & Lee and Al-Hawamdeh, 2002; Bakhari and Zawiyah, 2008; Bakhari and Zawiyah, 2008 \\
\hline Values & $\begin{array}{l}\text { Delong and Fahey, 2000; DeLong, 2004; Bock et al., 2005; Devos \& Willem, 2006; Michailova } \\
\text { and Minbaeva, } 2012\end{array}$ \\
\hline $\begin{array}{ll}\text { Social } & \text { Environment/ } \\
\text { Network } & \end{array}$ & $\begin{array}{l}\text { Hollander and Howard, 2000; Kubo, Saka and Pam, 2001; Lang, 2001; Thomas-Hunt, Reagans } \\
\text { \& McEvily, 2003; Phillips et al., 2004; Cross \& Cummings, 2004; Hansen et al., 2005; Small } \\
\text { and Sage, 2006; Chen et al., 2009; Wang and Noe, 2010; Borges, } 2012\end{array}$ \\
\hline $\begin{array}{l}\text { Organizational } \\
\text { Commitment }\end{array}$ & Jacobs and G. Roodt, 2007; Hassan, \& AL-Hakim, 2011; Kathiravelu, 2013 \\
\hline Size & Serenko et al., 2007 \\
\hline Climate & $\begin{array}{l}\text { Taylor and Wright, 2004; Bock et al., 2005; Suveatwatanakul, 2013; Chiu et al., 2006; Chow } \\
\text { and Chan, 2008; He and Wei, 2009; Hooff and Huysman, 2009; Hsu and Lin, 2008; Panteli and } \\
\text { Sockalingam, 2005; Shin et al., 2007). }\end{array}$ \\
\hline Top Management Support & $\begin{array}{l}\text { Connelly and Kelloway, 2003; Connelly \& Kelloway, 2003; MacNeil, 2004; Lin and Lee, 2004; } \\
\text { Lee et al., 2006; Lin, 2007; King and Marks, 2008; Wang and Noe, 2010; Wang and Noe, 2010; } \\
\text { Yiu and Law, } 2012\end{array}$ \\
\hline Openness and Fairness & $\begin{array}{l}\text { Bartol and Srivastava, 2002; Greenberg and Colquitt, 2005; Cabrera et al., 2006; Tsai and } \\
\text { Cheng, 2011; Yiu and Law, } 2012\end{array}$ \\
\hline Fellow Workers Support & Ju, Li, \& Lee, 2006; Wei, Teh, \& Asmawi, 2012; Kathiravelu, 2013 \\
\hline
\end{tabular}

2.1.9. Openness and Fairness: Study [37] viewed openness as the partner's willingness to communicate and interact, but on other side, only be willing to share selectively and on specific subjects that do not negatively affect their own interests [29]. From the organizational perspective, if employees cannot freely or are not allowed to share information, knowledge, ideas, or views about their work without a superior's permission, they will exhibit a passive manner in KS. However employees who are high in openness are more engaged in KS activities [38]. Reference [39], who also support this view, argue that openness influences the transfer of knowledge between partners. In addition, openness is a strong predictor of KS because openness to experience is a reflection of a person's curiosity and originality, which in turn are predictors of seeking other people's views and insights [38], [40].

Researchers [41] argued that when people feel their organizational environment is fair, they display a high level of KS behavioral intention based on their perceptions of trust and commitment [29].

2.1.10. Climate: Organizational climate is an important determinant of intention to share knowledge [15]. A climate encourages new ideas and focused on learning from failure was positively related to effective knowledge sharing [42], [5]. Previous studies also emphasized that equal climate encourages knowledge sharing [43], [44], [45], [46].

2.1.11. Fellow workers support: The interaction that exists between the workers and other employees can greatly impact knowledge sharing among them [47]. If employees realize that their co-worker are their partners, then will help one another in their task as well as their view to knowledge sharing will become favorable [48].

2.1.12. Organizational commitment: Organizational commitment has a positive impact on knowledge sharing. Study [7] suggested that when people are committed to their organization then they will think for the overall benefit of the organization and that is possible by increasing the overall productivity of employees which can be achieved through knowledge sharing.

2.1.13. Organizational environment: Employee's beliefs about the extent to which their organization has fairly fulfilled its obligations to them would affect their KS behaviors in informal interactions within the organization [49]. When people feel their organizational environment is fair, they display a high level of KS behavioral [41]. Previous Research has shown that employees are more committed to the organization, have more trust and are more satisfied when perceived as being fair [50], [51], [29]. Therefore, if organizational practices are perceived to be equitable and non arbitrary or capricious [26], employees are more likely to share their knowledge and expertise with others.

\section{Conceptual Framework}

The purpose of this study is to develop a suitable model and examines the possible relationships between organizational factors and knowledge sharing. This review reflects an influence of organizational factors on knowledge sharing via explicit and tacit knowledge sharing. The conceptual framework shown in Fig. 
1 shows the three emphasis areas of organizational factors and examines the relationships between each area of emphasis with knowledge sharing. In this framework, knowledge sharing (explicit and tacit knowledge sharing) is the dependent variables and organizational factors are taken as independent variables. The independent variables as shown in the dark shaded boxes with solid lines have been examined in most of the literature while the factors shown in the light shaded boxes with dotted lines are the less researched area and white boxes with close dotted lines are the least research areas which needs further research attention.

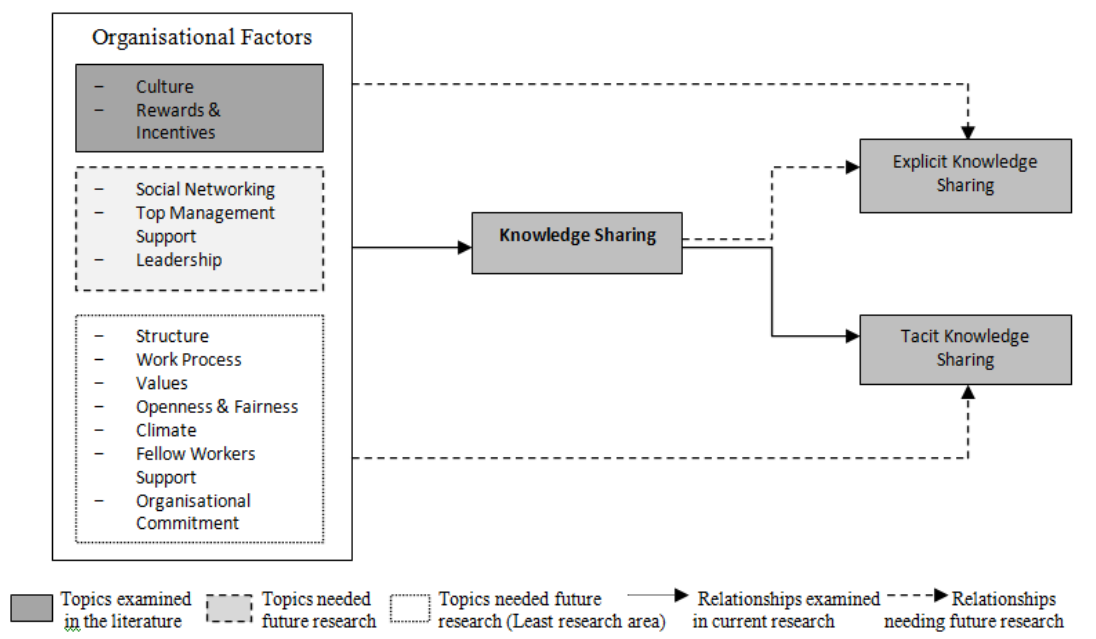

Fig1: Framework of organizational factors on knowledge sharing

\section{Future Directions of Knowledge Sharing Research}

Organizational factors influences knowledge sharing directly but the dearth of research is found in context of tacit and explicit knowledge sharing. Moreover, future studies should distinguish between sharing of tacit and explicit knowledge as they are quite different in nature. This paper categorized the organizational factors into three parts as most repeatedly used factors, less researched factors and least researched factors. Thus, this study suggests that these critical factors need to be investigated further and can be examined empirically.

\section{Conclusion}

In the knowledge-based era, Survival of any organization heavily depends on knowledge sharing, therefore, how to motivate employees to share their knowledge are the core and most difficult activity of KM. For this purpose this paper conceptually linked some of the organizational factors to knowledge sharing. This review also provides a conceptual framework, and identifies new factors for future research. This review highlights that although there is a growing literature on knowledge sharing, however, it is suggested that future research can focus on knowledge-sharing-related studies in multidisciplinary fields to present the factors affecting knowledge contribution more comprehensively.

\section{References}

[1] R. M. Grant, Toward a knowledge-based theory of the firm, Strategic Management Journal, 17, 1996, 109-122.

[2] J. C. Spender, \& R. M. Grant, Knowledge and the firm: Overview, Strategic Management Journal, 17, $1996,5-9$.

[3] T. H. Davenport, \& L. Prusak, Working knowledge: How organizations manage what they know (Harvard Business School Press, Boston, 1998)

[4] N. J. Foss, \& T. Pedersen, Transferring knowledge in MNCs: The role of sources of subsidiary knowledge and organizational context, Journal of International Management, 8(1), 2002, 49-67.

[5] S. Wang, \& R. A. Noe, Knowledge sharing: A review and directions for future research, Human Resource Management Review, 20(2), 2010, 115-131.

[6] N. M. Noor, and J. Salim, Factors influencing employee knowledge sharing capabilities in electronic government agencies in Malaysia, International Journal of Computer Science Issues (IJCSI), 8(4), 2011, 106-114.

[7] M. Rehman, A. K. B. Mahmood, R. Salleh, \& A. Amin, Review of Factors Affecting Knowledge Sharing Behavior, International Conference on E-business, Management and Economics, IACSIT Press, Hong Kong, 3, 2011, 223-227.

[8] B. Obrenovic, \& Y. Qin, Understanding the concept of individual level knowledge sharing: A review of critical success factors, Information and Knowledge Management, 4(4), 2014, 110-119.

[9] T. H. Davenport, Some Principles of Knowledge Management, Business and Strategy, 7, 1995, 34-41.

[10] I. Nonaka, A dynamic theory of organizational knowledge creation, Organization Science, 5(1), 1994, 14-37.

[11] C. McInerney, Knowledge management and the dynamic nature of knowledge, Journal of the American Society for Information Science and Technology, 53(12), 2002, 1009-1018.

[12] D. A. Schon, The reflective practitioner (Basic Books, New York, 1983). 
[13] I. Nonaka, R. Toyama, and N. Konno, SECI, Ba and Leadership: A unified model of dynamic knowledge creation, Long range planning, 33(1), 2000, 5-34.

[14] A. Lam, Tacit knowledge, organizational learning and societal institutions: an integrated framework, Organization Studies, 21(3), 2000, 487- 513.

[15] R. Borges, Tacit knowledge sharing between IT workers: The role of organizational culture, personality, and social environment, Management Research Review, 36(1), 2012, 89-108.

[16] R. McDermott, \& C. O'Dell, Overcoming cultural barriers to sharing knowledge, Journal of Knowledge Management, 5(1), 2001, 76-85.

[17] S.G. Goh, Managing effective knowledge transfer: an integrative framework and some practice implication, Journal of Knowledge Management, 6(1), 2002, 22-30.

[18] A. K. Gupta, and V. Govindarajan, Knowledge management's social dimension: Lessons from Nucor Steel, Sloan Management Review, 42(1), 2000, 71-80.

[19] V. Suppiah, \& M. S. Sandhu, Organizational culture's influence on tacit knowledge-sharing behavior, Journal of Knowledge Management, 15(3), 2011, 462-477.

[20] B. Sandhawalia, \& D. Dalcher, Knowledge management capability framework, IFIP 20th World Computer Congress, Conference on Knowledge Management in Action, Ackerman, M., DiengKuntz, R., Simone, C. \& Wulf, V. (eds.), New York, Springer, 2008, $165-180$

[21] S. Kim, \& H. Lee, The impact of organizational context and information technology on employee knowledge-sharing capabilities, Public Administration Review, 66(3), 2006, 370-385.

[22] S. Alam, Z. Abdullah, N. Ishak, \& Z. Zain, Assessing knowledge sharing behaviour among employees in SMEs: An empirical study, International Business Research, 2(2), 2009, 115-122.

[23] 23.A. Al-Alawi, N. Al-Marzooqi, \& Y. Mohammed, Organizational culture and knowledge sharing: Critical success factors, Journal of Knowledge Management, 11(2), 2007, 22-42.

[24] A. Kankanhalli, B. C. Y. Tan, \& K. K. Wei, Contributing knowledge to electronic knowledge repositories: An empirical investigation, MIS Quarterly, 29(1), 2005, 113-143.

[25] M. M. Wasko, and S. Faraj, Why should I share? Examining knowledge contribution in networks of practice, MIS Quarterly, 29(1), 2005, 35-57.

[26] G.W. Bock, and Y.G. Kim, Breaking the myths of rewards: An exploratory study of attitudes about knowledge sharing, Information Resources Management Journal, 15(2), 2002, 14-21.

[27] Bock et al., Behavioral intention formation in knowledge sharing: Examining the roles of extrinsic motivators, social-psychological forces, and organizational climate, MIS Quarterly, 29(1), 2005, 87-111.

[28] S. Watson, and K. Hewett, A multi-theoretical model of knowledge transfer in organizations: Determinants of knowledge contribution and knowledge reuse, Journal of Management Studies, 43(2), 2006, 141-173.

[29] M. Yiu, and R. Law, Factors influencing knowledge sharing behavior: A social-psychological view in tourism, Service Science, 3(2), 2012, 11-31.

[30] J. Boissevain, Friends of friends: Networks, manipulators and coalition, 24 (St. Martin's Press, 1974).

[31] J. H. Lee, Y. G. Kim, \& M. Y. Kim, Effects of managerial drivers and climate maturity on knowledge management performance: empirical validation, Information Resources Management Journal, 19(3), 2006, 48-60.

[32] W.R. King, and P.V. Marks, Motivating knowledge sharing through a knowledge management system, Omega, 36(1), 2008, 131146.

[33] S. Søndergaard, M. Ker, \& C. Clegg, Sharing knowledge: Contextualizing socio-technical thinking and practice, The Learning Organization, 14(5), 2007, 423-435.

[34] A. Srivastava, K. M. Bartol, and E. A. Locke, Empowering leadership in management teams: Effects on knowledge sharing, efficacy, and performance, Academy of Management Journal, 49(6), 2006, 1239-1251.

[35] S. Michailova, and D. B. Minbaeva, Organizational values and knowledge sharing in multinational corporations: The Danisco case, International Business Review, 21, 2012, 59-70.

[36] W. David, \& L. Fahey, Diagnosing cultural barriers to knowledge management, The Academy of Management Executive, 14(4), 2000, 113-127.

[37] R. Stata, Organizational learning - the key to management innovation, Sloan Management Review, 30(3), 1989, 63-74.

[38] A. Cabrera, W. C. Collins, and J. F. Salgado, Determinants of individual engagement in knowledge sharing, The International Journal of Human Resources Management, 17(2), 2006, 245-64.

[39] C. Lane, and R. Bachmann, Trust within and between organizations (Oxford University Press, New York, 1998).

[40] Matzler et. al., Personality traits and knowledge sharing, Journal of Economic Psychology, 29, 2008, 301-313.

[41] M. T. Tsai, and N. C. Cheng, Understanding knowledge sharing between IT professionals - An integration of social cognitive and social exchange theory, Behavior \& Information Technology, 1(1), 2011, 1-12

[42] W. A. Taylor, \& G. H. Wright, Organizational readiness for successful knowledge sharing: Challenges for public sector managers, Information Resources Management Journal, 17(2), 2004, 22-37.

[43] C. M. Chiu, M. H. Hsu, \& E. T. G. Wang, Understanding knowledge sharing in virtual communities: An integration of social capital and social cognitive theories, Decision Support Systems, 42(3), 2006, 1872-1888.

[44] W. S. Chow, \& L. S. Chan, Social network, social trust and shared goals in organizational knowledge sharing, Information \& Management, 45(7), 2008, 458-465.

[45] W. He, \& K. K. Wei, What drives continued knowledge sharing? An investigation of knowledge contribution and seeking beliefs, Decision Support Systems, 46(4), 2009, 826-838.

[46] C. L. Hsu, \& J. C. C. Lin, Acceptance of blog usage: The roles of technology acceptance, social influence and knowledge sharing motivation, Information \& Management, 45(1), 2008, 65-74.

[47] C. C. Wei, P. Teh, \& A. Asmawi, Knowledge sharing practices in Malaysian MSC status companies, Journal of Knowledge Management Practice, 13(1), 2012 , (online) http://www.tlainc.com/articl292.htm (Accessed 25 June 2016).

[48] T. L. Ju, C. Y. Li, and T. S. Lee, A contingency model for knowledge management capability and innovation, Industrial Management \& Data Systems, 106(5/6), 2006, 855-77.

[49] K. M. Bartol, and A. Srivastava, Encouraging knowledge sharing: The role of organizational reward systems, Journal of Leadership \& Organizational Studies, 9(1), 2002, 64-76.

[50] J. Greenberg, and J. Colquitt, Handbook of organizational justice (Lawrence Erlbaum Associates Publishers, Mahwah, NJ, 2005).

[51] R. Moorman, Relationship between organizational justice and organizational citizenship behaviors: Do fairness perceptions influence employee citizenship, Journal of Applied Psychology, 76(6), 1991, 845-855. 